\title{
Pemetrexed-Induced Rash May Be Prevented by Supplementary Corticosteroids
}

\author{
Takumi Sakurada, ${ }^{*, a}$ Soji Kakiuchi, ${ }^{b, c}$ Soichiro Tajima, ${ }^{d}$ Yuya Horinouchi, ${ }^{a}$ \\ Ken Konaka, ${ }^{a}$ Naoto Okada, ${ }^{a}$ Hirotaka Nishisako, ${ }^{a}$ Toshimi Nakamura, ${ }^{a}$ Kazuhiko Teraoka, ${ }^{a}$ \\ Kazuyoshi Kawazoe, ${ }^{a, e}$ Hiroaki Yanagawa, ${ }^{f}$ Yasuhiko Nishioka, ${ }^{c}$ and Keisuke Ishizawa ${ }^{a, e}$ \\ ${ }^{a}$ Department of Pharmacy, Tokushima University Hospital; 2-50-1 Kuramoto-cho, Tokushima 770-8503, Japan: \\ ${ }^{b}$ Department of Medical Oncology, Institute of Biomedical Sciences, The University of Tokushima Graduate School; \\ 3-8-15 Kuramoto-cho, Tokushima 770-8503, Japan: ${ }^{c}$ Department of Respiratory Medicine and Rheumatology, \\ Institute of Biomedical Sciences, The University of Tokushima Graduate School; 3-8-15 Kuramoto-cho, Tokushima \\ 770-8503, Japan: ${ }^{d}$ Department of Pharmacy, Kyushu University Hospital; 3-1-1 Maidashi, Higashi-ku, Fukuoka \\ 812-8582, Japan: ${ }^{e}$ Department of Clinical Pharmacy, Institute of Biomedical Sciences, The University of Tokushima \\ Graduate School; 2-50-1 Kuramoto-cho, Tokushima 770-8503, Japan: and ${ }^{f}$ Clinical Trial Center for Developmental \\ Therapeutics, Tokushima University Hospital; 2-50-1 Kuramoto-cho, Tokushima 770-8503, Japan.
}

Received May 22, 2015; accepted August 15, 2015

Pemetrexed, a chemotherapeutic drug, is highly active in non-small cell lung cancer and malignant pleural mesothelioma. Unfortunately, rashes are more commonly associated with pemetrexed than other chemotherapies, and it is recommended that patients receive corticosteroids ( $8 \mathrm{mg} / \mathrm{d}$ of dexamethasone) for $3 \mathrm{~d}$, including the day of pemetrexed administration (day 1). However, the efficacy of corticosteroids in this context has not been fully verified. In this retrospective study, we evaluated the medical records of 78 patients who received pemetrexed between April 2009 and March 2014, to confirm whether supplementary corticosteroids prevented rash development. The incidence of rash was lower in the 47 patients who received supplementary corticosteroids (after day 1) compared with the incidence among the 31 patients who did not receive supplementary corticosteroids $(\mathbf{1 9 . 1 \%}$ vs. $\mathbf{3 8 . 7 \%})$. The average cutoff dosage of supplementary corticosteroids on day 2 and day 3 was $1.5 \mathrm{mg} / \mathrm{d}$ of dexamethasone, as calculated using the receiver operating characteristic curve, and the odds ratio was 0.33 (95\% confidence interval: $0.12-0.94)$. Administration of $\geq 1.5 \mathrm{mg}$ of corticosteroids on day 2 and day 3 significantly reduced the severity of the rash compared to no supplementary treatment (grades $2 / 3,13.3 \%$ vs. $33.3 \%, p<0.05$ ). However, increasing the dose of corticosteroids had no additional effect on rash development. These results suggest that $\geq 1.5 \mathrm{mg}$ of supplementary dexamethasone on day 2 and day 3 (in addition to day 1) may be necessary for preventing pemetrexed-induced rash, but high doses of dexamethasone (e.g., $8 \mathrm{mg} / \mathrm{d})$ are unnecessary.

Key words pemetrexed; rash; dexamethasone; corticosteroid; risk factor

Pemetrexed (Alimta, Eli Lilly and Co.) is a novel multitargeted antifolate that inhibits thymidylate synthase, dihydrofolate reductase, and glycinamide ribonucleotide formyltransferase. ${ }^{1,2)}$ These multiple targets may explain the broad and preferable antitumor activity of pemetrexed, which has been evaluated in non-small cell lung cancer (NSCLC), malignant pleural mesothelioma (MPM), head, neck, cervical, breast, gastric, colorectal, pancreatic, and bladder cancers. ${ }^{3-14)}$ Pemetrexed is currently approved in combination with platinum (cisplatin or carboplatin) as a first-line treatment, and as a single-agent second-line treatment, for MPM and NSCLC. ${ }^{15,16)}$ Moreover, cisplatin plus pemetrexed provides improved survival and reduced toxicity in patients with non-squamous NSCLC, compared to cisplatin plus gemcitabine. ${ }^{17)}$

Interestingly, multivariate analysis has revealed that increasing levels of homocysteine and methylmalonic acid are correlated with a toxic increase in pemetrexed. ${ }^{18)}$ The risks associated with severe pemetrexed toxicity, such as neutropenia, thrombocytopenia, infection, and diarrhea, can be reduced by decreasing homocysteine and methylmalonic acid levels by supplementing patients with folic acid and vitamin $\mathrm{B}_{12}{ }^{18)}$ Unfortunately, rash is one of the most common adverse events that is associated with pemetrexed treatment. In a phase I trial (solid tumors) and a phase II trial (NSCLC), the incidence of rash without corticosteroids was $90.3 \%$ and $73.8 \%$, respectively. ${ }^{19,20)}$ In contrast, rash occurred in only $32.0 \%$ of patients who were treated with cisplatin and pemetrexed, with supplemental corticosteroids to prevent nausea and vomiting. ${ }^{21)}$ Moreover, in several clinical trials to evaluate the efficacy and safety of pemetrexed, patients who received pemetrexed with dexamethasone (4 mg orally twice daily for $3 \mathrm{~d}$, including the day of pemetrexed administration [day 1]) tended to have a lower frequency and severity of rash..$^{3,12,22}$ Therefore, it is recommended that patients receive dexamethasone to prevent rash when undergoing pemetrexed treatment. However, it is unclear whether corticosteroids can ameliorate pemetrexedinduced rash.

In this retrospective study, we assessed whether supplementary corticosteroids reduced the incidence of rash. In addition, we evaluated the association between rash development and the corticosteroid dosage or period of administration.

\section{MATERIALS AND METHODS}

Patients and Methods We retrospectively investigated the medical records of patients with MPM or NSCLC who were treated with pemetrexed for the first time between April 2009 and March 2014 in the Department of Respiratory Medi- 
cine and Rheumatology at Tokushima University Hospital. These patients received corticosteroids as clinical practice for various purposes, such as preventing nausea and vomiting. Recorded patient characteristics included age, sex, laboratory data, body temperature, Eastern Cooperative Oncology Group performance status (PS), histology, clinical staging, history of treatment, dosage or period of corticosteroids for 1 week after pemetrexed administration, and the presence of a pemetrexedinduced rash within 3 weeks of treatment. We excluded all patients who might have developed a rash due to antibiotic treatment, as we would not have been able to evaluate the influence of pemetrexed. In addition, we excluded patients who had received corticosteroids for long periods $(>2 \mathrm{~d}$ after pemetrexed administration).

Creatinine clearance was calculated as described by Cockcroft and Gault. ${ }^{23)}$ Fever and C-reactive protein (CRP) levels were evaluated within 1 week of pemetrexed administration, before the patient developed hematological toxicity. We defined CRP elevation as an increase from below the mild level $(<1.0 \mathrm{mg} / \mathrm{dL})$ to above the moderate level $(1.0-10.0 \mathrm{mg} / \mathrm{dL})$, or from below the moderate level to above the severe level $(>10.0 \mathrm{mg} / \mathrm{dL})$. The dosage of supplementary corticosteroids was converted into a corresponding dosage of dexamethasone. Adverse events following pemetrexed administration were evaluated according to the Common Terminology Criteria for Adverse Events version 3.0.

This study protocol was reviewed and approved by the Ethics Committee of Tokushima University Hospital (approval number: 1403).

Statistical Analysis We used Ekuseru-Toukei 2011 software (Social Survey Research Information Co., Tokyo) to conduct the statistical analyses. All comparisons between groups were performed by using the $\chi^{2}$ test or Fisher's exact test, as appropriate. We calculated the area under the receiver operating characteristic (ROC) curve to estimate the cutoff value for dosage of corticosteroids. Univariate analyses were performed to identify the relationship between pemetrexed-induced rash and corticosteroids or other factors. $p$-Values of $<0.05$ were considered statistically significant.

\section{RESULTS}

Patient Characteristics The clinical characteristics of the 78 patients who were included in this study are listed in Table 1. The median age was 67.5 years (range, $43-84$ years), and 15 (19.2\%) patients were $\geq 75$ years old. Regarding the histological type of the cancer, $73(93.6 \%)$ patients had NSCLC and 5 (6.4\%) patients had MPM. Pemetrexed was frequently administrated as a single agent $(38 / 78,48.7 \%)$, or in combination with cisplatin $(10 / 78,12.8 \%)$, carboplatin $(17 / 78,21.8 \%)$, or bevacizumab $(21 / 78,26.9 \%)$. Most patients received $500 \mathrm{mg} /$ $\mathrm{m}^{2}$ of pemetrexed, although one patient received a lower dose of pemetrexed $\left(400 \mathrm{mg} / \mathrm{m}^{2}\right)$ based on their clinical condition. Patients were instructed to begin taking folic acid $(500 \mu \mathrm{g} / \mathrm{d})$ orally at least 1 week before pemetrexed administration (day 1). Vitamin $B_{12}(1 \mathrm{mg})$ was provided by intramuscular injection at least 1 week before day 1 , and the injection was repeated every 9 weeks. Corticosteroids were administered to all patients as clinical practice for anticipated side effects, such as vomiting, nausea, fatigue, and rash.

The Incidence Rate and Risk Factors for Pemetrexed-
Table 1. Patient Characteristics

\begin{tabular}{|c|c|}
\hline No. of patients & 78 \\
\hline \multicolumn{2}{|l|}{ Age (years) } \\
\hline Median (range) & $67.5(43-84)$ \\
\hline \multicolumn{2}{|l|}{ Sex } \\
\hline Female & $34(43.6 \%)$ \\
\hline Male & $44(56.4 \%)$ \\
\hline \multicolumn{2}{|l|}{ Performance status } \\
\hline $0 / 1$ & $67(85.9 \%)$ \\
\hline $2 / 3$ & $11(14.1 \%)$ \\
\hline \multicolumn{2}{|l|}{ Histology } \\
\hline Malignant pleural mesothelioma & $5(6.4 \%)$ \\
\hline Adenocarcinoma & $63(80.8 \%)$ \\
\hline Squamous cell carcinoma & $1(1.3 \%)$ \\
\hline NSCLC (NOS) & $8(10.3 \%)$ \\
\hline Others & $1(1.3 \%)$ \\
\hline \multicolumn{2}{|l|}{ Stage } \\
\hline$\leq \mathrm{IIB}$ & $2(2.6 \%)$ \\
\hline IIIA/IIIB & $9(11.5 \%)$ \\
\hline IV & $67(85.9 \%)$ \\
\hline \multicolumn{2}{|l|}{ Previous chemotherapy } \\
\hline Yes & $55(70.5 \%)$ \\
\hline No & $23(29.5 \%)$ \\
\hline \multicolumn{2}{|l|}{ PEM regimen } \\
\hline PEM alone & $38(48.7 \%)$ \\
\hline $\mathrm{PEM}+\mathrm{CDDP}$ & $7(9.0 \%)$ \\
\hline $\mathrm{PEM}+\mathrm{CBDCA}$ & $12(15.4 \%)$ \\
\hline PEM+bevacizumab & $13(16.7 \%)$ \\
\hline PEM+CDDP + bevacizumab & $3(3.8 \%)$ \\
\hline $\mathrm{PEM}+\mathrm{CBDCA}+$ bevacizumab & $5(6.4 \%)$ \\
\hline
\end{tabular}

NSCLC, non-small cell lung cancer; NOS, not-otherwise specified; PEM, pemetrexed; CDDP, cisplatin; CBDCA, carboplatin.

Induced Rash Among the 78 enrolled patients, 21 (26.9\%) patients developed pemetrexed-induced rash that corresponded to grades $1(5.1 \%), 2(19.2 \%)$, and $3(2.6 \%)$. The incidence of pemetrexed-induced rash was low among patients who received supplementary corticosteroid treatment after day 1 , compared to among patients who did not receive supplementary treatment (19.1\% vs. $38.7 \%$ ), although this difference was not statistically significant (Table 2). Similarly, no significant differences were observed for all patient characteristics between the groups that did and did not develop pemetrexedinduced rash (Table 2).

The Effect of Supplementary Corticosteroids on Pemetrexed-Induced Rash Because previous studies have reported that $3 \mathrm{~d}$ of corticosteroid treatment (including day 1) can effectively ameliorate pemetrexed-induced rash, ${ }^{3,4,12,22,24)}$ we also investigated the effect of supplementary corticosteroids. The cutoff value was found to be $1.5 \mathrm{mg}$ of dexamethasone based on the ROC curve, which was calculated using the average dosage of the supplementary corticosteroids (area under the curve: 0.63$)$. In the univariate analysis, supplementary corticosteroid treatment ( $\geq 1.5 \mathrm{mg}$ of dexamethasone) on day 2 and day 3 was the only factor that affected rash development, and the odds ratio (OR) for supplementary corticosteroid treatment was 0.33 (95\% confidence interval [CI]: 0.12-0.94) (Table 3). Administration of $\geq 1.5 \mathrm{mg}$ of dexamethasone on day 2 and day 3 significantly reduced the frequency and severity of rash compared to no supplementary treatment (all grades, $17.8 \% v s$. $39.4 \%, p<0.05$; grades $2 / 3,13.3 \%$ vs. $33.3 \%, p<0.05$ ) (Table 
3). Interestingly, supplementary corticosteroids on day 2 and day 3 had no dose-dependent effect on rash development (Fig. 1).

The Effect of Supplementary Corticosteroids on Other

Table 2. The Relationships between Clinical Variables and PemetrexedInduced Rash

\begin{tabular}{|c|c|c|c|c|}
\hline \multirow{2}{*}{ Variables } & \multicolumn{2}{|r|}{ Rash } & \multirow{2}{*}{$p$} & \multirow{2}{*}{$\begin{array}{c}\text { Univariate analysis } \\
\text { Odds ratio }(95 \% \mathrm{CI})\end{array}$} \\
\hline & None & Incidence $(\%)$ & & \\
\hline \multicolumn{5}{|l|}{ Age } \\
\hline$<75$ years & 44 & $19(30.2)$ & $0.33^{b)}$ & \multirow[b]{2}{*}{$0.36(0.07-1.73)$} \\
\hline$\geq 75$ years & 13 & $2(13.3)$ & & \\
\hline \multicolumn{5}{|l|}{ Sex } \\
\hline Female & 25 & $9(26.5)$ & $0.94^{a)}$ & \multirow[b]{2}{*}{$1.04(0.38-2.86)$} \\
\hline Male & 32 & $12(27.3)$ & & \\
\hline \multicolumn{5}{|c|}{ Creatinine clearance } \\
\hline$\geq 45 \mathrm{~mL} / \mathrm{min}$ & 51 & $20(28.2)$ & $0.67^{b)}$ & \multirow[b]{2}{*}{$0.43(0.05-3.76)$} \\
\hline$<45 \mathrm{~mL} / \mathrm{min}$ & 6 & $1(14.3)$ & & \\
\hline \multicolumn{5}{|c|}{ Performance status } \\
\hline $0 / 1$ & 48 & $19(28.4)$ & $0.72^{b)}$ & \multirow[b]{2}{*}{$0.56(0.11-2.84)$} \\
\hline$\geq 2$ & 9 & $2(18.2)$ & & \\
\hline \multicolumn{5}{|c|}{ Previous chemotherapy } \\
\hline None & 18 & $5(21.7)$ & $0.51^{a)}$ & \multirow[b]{2}{*}{$1.48(0.47-4.66)$} \\
\hline Exist & 39 & $16(29.1)$ & & \\
\hline \multicolumn{5}{|c|}{ Supplementary corticosteroids* } \\
\hline None & 19 & $12(38.7)$ & $0.06^{a)}$ & \multirow[b]{2}{*}{$0.38(0.13-1.04)$} \\
\hline Exist & 38 & $9(19.1)$ & & \\
\hline \multicolumn{5}{|c|}{ Bevacizumab combination } \\
\hline No & 42 & $15(26.3)$ & $0.84^{a)}$ & \multirow[b]{2}{*}{$1.12(0.37-3.42)$} \\
\hline Yes & 15 & $6(28.6)$ & & \\
\hline \multicolumn{5}{|c|}{ Platinum-based combination } \\
\hline No & 35 & $16(31.4)$ & $0.22^{a)}$ & \multirow[b]{2}{*}{$0.50(0.16-1.55)$} \\
\hline Yes & 22 & $5(18.5)$ & & \\
\hline
\end{tabular}

* Supplementary corticosteroids on day 2 and day 3 after the day of pemetrexed administration. a) $\chi^{2}$ test. $b$ ) Fisher's exact test.
Adverse Events Pemetrexed has other common adverse events, which include hepatopathy, transient fever, and elevated CRP levels. Among the patients without supplementary corticosteroid treatment after day 1, high incidences of elevated aspartate aminotransferase (AST), alanine aminotransferase (ALT), and gamma-glutamyl transpeptidase ( $\gamma$-GTP) levels were detected (Table 4). In contrast, supplementary corticosteroids suppressed transient fever $(6.5 \%$ vs. $22.6 \%)$ and elevated CRP levels (25.6\% vs. 44.4\%) (Table 4), although these differences were not statistically significant (Table 4).

\section{DISCUSSION}

Pemetrexed is associated with a high incidence of rash, and is occasionally responsible for more severe symptoms, such as acute generalized exanthematous pustulosis ${ }^{25)}$ and Lyell's syndrome. ${ }^{26,27)}$ Therefore, it is important to prevent the development of rash and to decrease its severity. Pemetrexed is asso-

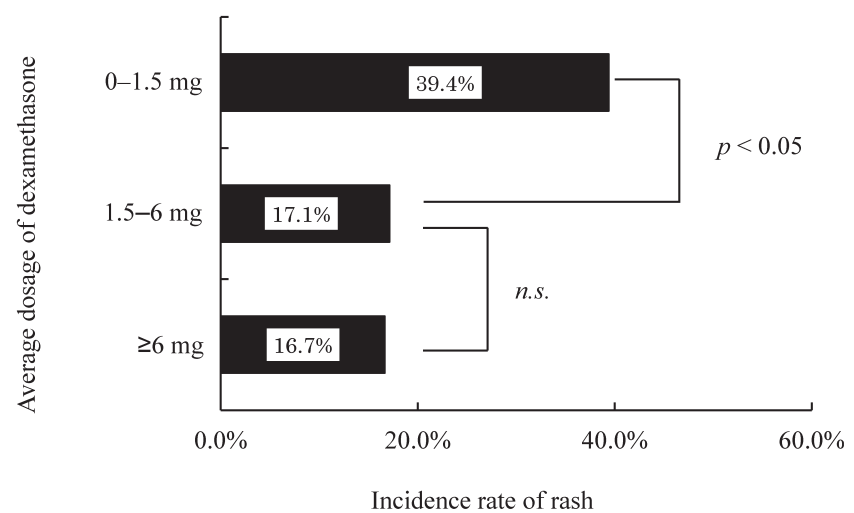

Fig. 1. The Effect of Supplementary Corticosteroids on Day 2 and Day 3 after the Day of Pemetrexed Administration

n.s.; not statistically significant.

Table 3. The Effect of Supplementary Corticosteroids on Pemetrexed-Induced Rash among the 78 Patients Who Only Received Corticosteroids for $3 \mathrm{~d}$

\begin{tabular}{|c|c|c|c|c|c|c|c|}
\hline \multirow[b]{2}{*}{ Supplementary corticosteroids } & \multicolumn{3}{|c|}{ All grades } & \multicolumn{3}{|c|}{ Grades 2 and 3} & \multirow[b]{2}{*}{ Median (range) } \\
\hline & $\begin{array}{c}\text { Rash incidence } \\
(\%)\end{array}$ & $\begin{array}{l}\text { Odds ratio } \\
(95 \% \mathrm{CI})\end{array}$ & $p^{a)}$ & $\begin{array}{c}\text { Rash incidence } \\
(\%)\end{array}$ & $\begin{array}{l}\text { Odds ratio } \\
(95 \% \mathrm{CI})\end{array}$ & $p^{a)}$ & \\
\hline \multicolumn{8}{|l|}{ Dose on day 2 and day 3} \\
\hline Dexamethasone $<1.5 \mathrm{mg}(n=33)$ & $13(39.4)$ & & & $11(33.3)$ & & & $6.5(4-10)$ \\
\hline Dexamethasone $\geq 1.5 \mathrm{mg}(n=45)$ & $8(17.8)$ & $0.33(0.12-0.94)$ & 0.04 & $6(13.3)$ & $0.31(0.10-0.95)$ & 0.04 & $6(2-14)$ \\
\hline
\end{tabular}

a) Univariate analyses.

Table 4. The Effect of Dexamethasone on the Other Adverse Events That Were Associated with Pemetrexed Therapy

\begin{tabular}{|c|c|c|c|c|c|c|}
\hline \multirow{3}{*}{ Variables } & \multicolumn{3}{|c|}{ All grades } & \multicolumn{3}{|c|}{ Grade 3} \\
\hline & \multicolumn{2}{|c|}{ Supplementary corticosteroid incident no./all no. (\%) } & \multirow{2}{*}{$p$} & \multicolumn{2}{|c|}{ Supplementary corticosteroid incident no./all no. (\%) } & \multirow{2}{*}{$p$} \\
\hline & Non-administration & Administration & & Non-administration & Administration & \\
\hline AST & $7 / 31(22.6)$ & $15 / 47(31.9)$ & $0.37^{a)}$ & $1 / 31(3.2)$ & $2 / 47(4.3)$ & $1.00^{b)}$ \\
\hline ALT & 6/31 (19.4) & $13 / 47(27.7)$ & $0.43^{a)}$ & $1 / 31(3.2)$ & $1 / 47(2.1)$ & $1.00^{b)}$ \\
\hline T-BiL & $7 / 29(24.1)$ & $10 / 47(21.3)$ & $0.77^{a}$ & $1 / 29(3.4)$ & $0 / 47(0.0)$ & $0.38^{b)}$ \\
\hline$\gamma$-GTP & $3 / 29(10.3)$ & 9/47 (19.1) & $0.35^{b)}$ & $0 / 29(0.0)$ & $0 / 47(0.0)$ & - \\
\hline Transient fever & $7 / 31(22.6)$ & $3 / 46(6.5)$ & $0.08^{b)}$ & $0 / 31(0.0)$ & $0 / 46(0.0)$ & - \\
\hline CRP elevation & $12 / 27(44.4)$ & $11 / 43(25.6)$ & $0.10^{a)}$ & & & \\
\hline
\end{tabular}

AST, aspartate aminotransferase; ALT, alanine aminotransferase; T-BiL, total bilirubin; $\gamma$-GTP, gamma-glutamyl transpeptidase; CRP, C-reactive protein. $a$ ) $\chi^{2}$ test. $b$ ) Fisher's exact test. 
ciated with rash in $70-90 \%$ of patients who have not received corticosteroids, compared to in $14-50 \%$ of patients who have received corticosteroids. ${ }^{3,19-21,28)}$ However, one phase II study failed to mention the dose and dosing period of dexamethasone, and the efficacy of dexamethasone for rash prevention was not statistically analyzed. ${ }^{3)}$ In addition, two Japanese clinical trials did not give corticosteroids to all patients, ${ }^{19,20)}$ and supplementary corticosteroids were given to all patients for the prevention of nausea and vomiting in other trials. ${ }^{21,28)}$ Therefore, the statistical efficacy of corticosteroids for rash prevention in Japan remains unknown. As corticosteroid-associated adverse events are known to be dependent on the dose and duration of treatment, patients should receive the lowest possible dose of corticosteroids.

Previous studies have reported the ability of supplementary corticosteroids to suppress pemetrexed-induced rash, although this effect was not statistically significant. ${ }^{24,29)}$ Ishikawa et al. reported that the incidence of pemetrexed-induced rash was lower in patients who received supplementary corticosteroids, compared to that in patients who did not receive supplementary corticosteroids, although this difference was not statistically significant $(23.5 \%$ vs. $36.2 \%, p=0.17) .{ }^{24)}$ However, the absence of statistical significance might be related to the relatively low number of patients who were enrolled in that study $(n=81)$. In addition, those authors did not evaluate a cutoff dose or the dosing period. Another study has reported insignificant efficacy for corticosteroids, although that study only enrolled 23 patients. $^{29)}$ Furthermore, the authors re-counted patients who received multiple courses of pemetrexed therapy, and only used the Wilcoxon's $t$ test and Fisher's exact test. These methodological considerations may be responsible for the reported insignificant effect of supplementary corticosteroids on pemetrexed-induced rash. In the present study, we identified the effective cutoff dose of supplementary corticosteroids ( $\geq 1.5 \mathrm{mg} / \mathrm{d}$ dexamethasone on day 2 and day 3 ) for rash prevention after pemetrexed treatment. Even when the patients were treated with supplementary corticosteroids on day 2 and day 3 , rash occurred in $17.8 \%$ of the patients; increasing the dose of corticosteroids had no additional effect on rash development. Therefore, it may be necessary to continue corticosteroid administration for $>3 \mathrm{~d}$, or to provide antihistamine agents, for patients who exhibit pemetrexed-induced rash.

In this study, all patients received at least $3.3 \mathrm{mg}$ dexamethasone on day 1 to prevent nausea and vomiting. The incidence of rash in the patients who did not receive supplementary corticosteroids was lower in this study, compared to that in the previous clinical trials. ${ }^{3,19)}$ In addition, there was no correlation between the dose of dexamethasone and the incidence of rash in the patients who only received dexamethasone on day 1 (OR: 0.71, 95\% CI: 0.11-4.51). Therefore, receiving $3.3 \mathrm{mg}$ dexamethasone on day 1 might also be sufficient to prevent pemetrexed-induced rash.

Interestingly, pemetrexed is primarily excreted by the kidneys, and reduced renal function results in reduced clearance of pemetrexed and a subsequent increase in exposure. ${ }^{30}$ Therefore, it appears that rash development was independent of pemetrexed levels in the blood, as renal function did not correlate with rash development. However, one of the extraordinarily frequent adverse events of pemetrexed treatments is hepatic toxicity. ${ }^{20)}$ Supplementary corticosteroids did not sig- nificantly affect the elevated hepatic function after pemetrexed treatment, although the corticosteroids did appear to exacerbate the elevation in AST, ALT, and $\gamma$-GTP levels. Fortunately, supplementary corticosteroid treatment had no effect on grade 3 hepatic toxicity in this study, although a lower corticosteroid dose is considered appropriate, given the toxicity that is associated with pemetrexed. Similarly, pemetrexed treatment often causes transient fever and elevated CRP levels. In several cases, these decreased the patients' quality of life and resulted in unnecessary antibacterial agents being prescribed. Therefore, supplementary corticosteroid treatment may help reduce the number of unnecessary prescriptions by reducing the incidence of fever or elevated CRP levels.

This study retrospectively evaluated patients' medical records, and we demonstrated that corticosteroids were only effective for a range of dexamethasone doses ( $\geq 1.5 \mathrm{mg}$ ), which is a major limitation of this study. Furthermore, we determined the dexamethasone cutoff value using the ROC curve, although the area under the curve value $(0.63)$ was relatively low. Therefore, further studies should evaluate whether a fixed dose of corticosteroid (e.g., $1.5 \mathrm{mg}$ or $2.0 \mathrm{mg}$ ) is effective for pemetrexed-induced rash. Furthermore, we cannot completely exclude the possible influence of antiemetics or other drugs. However, rash development after pemetrexed administration was late-onset, and we assume that this rash was a characteristic adverse event of pemetrexed treatment.

In conclusion, we found that supplementing the initial treatment with $\geq 1.5 \mathrm{mg}$ of corticosteroids on day 2 and day 3 significantly suppressed rash development. As it is impossible to predict which patients are at high risk of rash development, all patients who receive pemetrexed should also receive a small amount of supplementary corticosteroids to prevent rash.

Conflict of Interest The authors declare no conflict of interest.

\section{REFERENCES}

1) Shih C, Habeck LL, Mendelsohn LG, Chen VJ, Schultz RM. Multiple folate enzyme inhibition: mechanism of a novel pyrrolopyrimidine-based antifolate LY231514 (MTA). Adv. Enzyme Regul., 38, 135-152 (1998).

2) Taylor EC, Patel HH. Synthesis of pyrazolo[3,4- $d]$ pyrimidine analogues of the potent antitumor agent $\mathrm{N}$-4-[2-(2-amino-4(3H)oxo-7H-pyrrolo[2,3- $d$ ]pyrimidin-5-yl)ethyl]benzoyl-L-glutamic acid (LY231514). Tetrahedron, 48, 8089-8100 (1992).

3) Rusthoven JJ, Eisenhauer E, Butts C, Gregg R, Dancey J, Fisher B, Iglesias J. Multitargeted antifolate LY231514 as first-line chemotherapy for patients with advanced non-small-cell lung cancer: A phase II study. National Cancer Institute of Canada Clinical Trials Group. J. Clin. Oncol., 17, 1194 (1999).

4) Vogelzang NJ, Rusthoven JJ, Symanowski J, Denham C, Kaukel E, Ruffie P, Gatzemeier U, Boyer M, Emri S, Manegold C, Niyikiza C, Paoletti P. Phase III study of pemetrexed in combination with cisplatin versus cisplatin alone in patients with malignant pleural mesothelioma. J. Clin. Oncol., 21, 2636-2644 (2003).

5) Hanauske AR, Chen V, Paoletti P, Niyikiza C. Pemetrexed disodium: a novel antifolate clinically active against multiple solid tumors. Oncologist, 6, 363-373 (2001).

6) Pivot X, Raymond E, Laguerre B, Degardin M, Cals L, Armand JP, Lefebvre JL, Gedouin D, Ripoche V, Kayitalire L, Niyikiza C, Johnson R, Latz J, Schneider M. Pemetrexed disodium in recurrent locally advanced or metastatic squamous cell carcinoma of the head 
and neck. Br. J. Cancer, 85, 649-655 (2001).

7) Goedhals L, van Wiyk AL, Smith BL, Fourie SJ. Pemetrexed (Alimta, LY231514) demonstrates clinical activity in chemonaive patients with cervical cancer in a phase II single-agent trial. Int. J. Gynecol. Cancer, 16, 1172-1178 (2006).

8) Spielmann M, Martin M, Namer M, duBois A, Unger C, Dodwell DJ. Activity of pemetrexed (ALIMTA, multitargeted antifolate, LY231514) in metastatic breast cancer patients previously treated with an anthracycline and a taxane: an interim analysis. Clin. Breast Cancer, 2, 47-51 (2001).

9) Martin M, Spielmann M, Namer M, duBois A, Unger C, Dodwell D, Vodvarka P, Lind M, Calvert H, Casado A, Zelek L, Lluch A, Carrasco E, Kayitalire L, Zielinski C. Phase II study of pemetrexed in breast cancer patients pretreated with anthracyclines. Ann. Oncol., 14, 1246-1252 (2003).

10) Miles DW, Smith IE, Coleman RE, Calvert AH, Lind MJ. A phase II study of pemetrexed disodium (LY231514) in patients with locally recurrent or metastatic breast cancer. Eur. J. Cancer, 37, 1366-1371 (2001).

11) Bajetta E, Celio L, Buzzoni R, Ferrari L, Marchianò A, Martinetti A, Longarini R, Becerra C, Ilardi C, John W. Phase II study of pemetrexed disodium (Alimta) administered with oral folic acid in patients with advanced gastric cancer. Ann. Oncol., 14, 1543-1548 (2003).

12) Cripps C, Burnell M, Jolivet J, Batist G, Lofters W, Dancey J, Iglesias J, Fisher B, Eisenhauer EA. Phase II study of first-line LY231514 (multi-targeted antifolate) in patients with locally advanced or metastatic colorectal cancer: an NCIC Clinical Trials Group study. Ann. Oncol., 10, 1175-1179 (1999).

13) John W, Picus J, Blanke CD, Clark JW, Schulman LN, Rowinsky EK, Thornton DE, Loehrer PJ. Activity of multitargeted antifolate (pemetrexed disodium, LY231514) in patients with advanced colorectal carcinoma: results from a phase II study. Cancer, 88, 1807-1813 (2000).

14) Miller KD, Picus J, Blanke C, John W, Clark J, Shulman LN, Thornton D, Rowinsky E, Loehrer PJ Sr. Phase II study of the multitargeted antifolate LY231514 (ALIMTA, MTA, pemetrexed disodium) in patients with advanced pancreatic cancer. Ann. Oncol., 11, 101-103 (2000).

15) National Comprehensive Cancer Network Guidelines. "Non-Small Cell Lung Cancer.”: 〈http://www.tri-kobe.org/nccn/guideline/lung/ english/non_small.pdf, cited 1 May, 2015.

16) National Comprehensive Cancer Network Guidelines. "Malignant Pleural Mesothelioma.”: 〈http://www.tri-kobe.org/nccn/guideline/ lung/english/mpm.pdf), cited 1 May, 2015.

17) Scagliotti GV, Parikh P, von Pawel J, Biesma B, Vansteenkiste J, Manegold C, Serwatowski P, Gatzemeier U, Digumarti R, Zukin M, Lee JS, Mellemgaard A, Park K, Patil S, Rolski J, Goksel T, de Marinis F, Simms L, Sugarman KP, Gandara D. Phase III study comparing cisplatin plus gemcitabine with cisplatin plus pemetrexed in chemotherapy-naïve patients with advanced-stage nonsmall-cell lung cancer. J. Clin. Oncol., 26, 3543-3551 (2008).

18) Niyikiza C, Baker SD, Seitz DE, Walling JM, Nelson K, Rusthoven JJ, Stabler SP, Paoletti P, Calvert AH, Allen RH. Homocysteine and methylmalonic acid: markers to predict and avoid toxicity from pemetrexed therapy. Mol. Cancer Ther., 1, 545-552 (2002).
19) Nakagawa K, Kudoh S, Matsui K, Negoro S, Yamamoto N, Latz JE, Adachi S, Fukuoka M. A phase I study of pemetrexed (LY231514) supplemented with folate and vitamin B12 in Japanese patients with solid tumours. Br. J. Cancer, 95, 677-682 (2006).

20) Ohe $Y$, Ichinose $Y$, Nakagawa K, Tamura T, Kubota K, Yamamoto N, Adachi S, Nambu Y, Fujimoto T, Nishiwaki Y, Saijo N, Fukuoka M. Efficacy and safety of two doses of pemetrexed supplemented with folic acid and vitamin $\mathrm{B}_{12}$ in previously treated patients with non-small cell lung cancer. Clin. Cancer Res., 14, 4206-4212 (2008).

21) Nakagawa K, Yamazaki K, Kunitoh H, Hida T, Gemba K, Shinkai T, Ichinose Y, Adachi S, Nambu Y, Saijo N, Fukuoka M. Efficacy and safety of pemetrexed in combination with cisplatin for malignant pleural mesothelioma: A Phases I/II Study in Japanese Patients. Jpn. J. Clin. Oncol., 38, 339-346 (2008).

22) Rinaldi DA, Kuhn JG, Burris HA, Dorr FA, Rodriguez G, Eckhardt SG, Jones S, Woodworth JR, Baker S, Langley C, Mascorro D, Abrahams T, Von Hoff DD. A phase I evaluation of multitargeted antifolate (MTA, LY231514), administered every 21 days, utilizing the modified continual reassessment method for dose escalation. Cancer Chemother. Pharmacol., 44, 372-380 (1999).

23) Cockcroft DW, Gault MH. Prediction of creatinine clearance from serum creatinine. Nephron, 16, 31-41 (1976).

24) Ishikawa H, Onishi T, Kobayashi R, Ohashi Y, Suzuki K, Yamamoto N, Shino M. Effectiveness of steroids for the rash side effect of pemetrexed. Gan To Kagaku Ryoho, 40, 75-78 (2013).

25) Bracke A, Van Marck E, Lambert J. Acute generalized exanthematous pustulosis after pemetrexed, and recurrence after re-introduction. Clin. Exp. Dermatol., 34, 337-339 (2009).

26) Bosch-Barrera J, Gaztañaga M, Ceballos J, Pérez-Gracia JL, LópezPicazo JM, García-Foncillas J, Ferrer M, Sanz ML, Pretel M, Idoate MA, Gil-Bazo I. Toxic epidermal necrolysis related to pemetrexed and carboplatin with vitamin $\mathrm{B}_{12}$ and folic acid supplementation for advanced non-small cell lung cancer. Onkologie, 32, 580-584 (2009).

27) Tummino C, Barlesi F, Tchouhadjian C, Tasei AM, Gaudy-Marqueste C, Richard MA, Astoul P. Severe cutaneous toxicity after Pemetrexed as second line treatment for a refractory non small cell lung cancer. Rev. Mal. Respir., 24, 635-638 (2007).

28) Hanna N, Shepherd FA, Fossella FV, Pereira JR, De Marinis F, von Pawel J, Gatzemeier U, Tsao TC, Pless M, Muller T, Lim HL, Desch C, Szondy K, Gervais R, Shaharyar, Manegold C, Paul S, Paoletti P, Einhorn L, Bunn PA Jr. Randomized phase III trial of pemetrexed versus docetaxel in patients with non-small-cell lung cancer previously treated with chemotherapy. J. Clin. Oncol., 22, 1589-1597 (2004).

29) Hayashi A, Nakamura N, Matsumura C, Hirai M, Kagomoto M, Ishizu M. Assessment of risk factors of rash associated with pemetrexed therapy. J. Jpn. Soc. Hosp. Pharm., 48, 4 (2012).

30) Mita AC, Sweeney CJ, Baker SD, Goetz A, Hammond LA, Patnaik A, Tolcher AW, Villalona-Calero M, Sandler A, Chaudhuri T, Molpus K, Latz JE, Simms L, Chaudhary AK, Johnson RD, Rowinsky EK, Takimoto CH. Phase I and pharmacokinetic study of pemetrexed administered every 3 weeks to advanced cancer patients with normal and impaired renal function. J. Clin. Oncol., 24, 552-562 (2006). 